\title{
Research on Development and Application of User Experience
}

\author{
Weisong Quan ${ }^{1, \text { a }}$ \\ ${ }^{1}$ School of Automation Engineering, University of Electronic Science and Technology of China, Chengdu \\ 611731, China. \\ a841513786@qq.com
}

Keywords: user experience, interface, interactive technology, usability.

\begin{abstract}
With the advent of the information age, the new and various information services appear, and a large number of people have a higher and higher requirement on the information service. In order to obtain user acceptance to service, the service provider must ensure a good user experience quality. Therefore, the quality of user experience has not only become one of the important research topics in academia, but also has become one of the key evaluation of industry. This paper systematically summarizes the concept, composition, evaluation standard and application research of user experience, and analyzes the evaluation criteria and development and application of user experience in detail. The research shows that the user experience is an important decision-making factor in product design. The existing research has different views on the definition and composition of the user experience, which leads to the difference of the user experience measurement and evaluation. The user experience objective measurement method and quantitative evaluation methods remain to be improved.
\end{abstract}

\section{Introduction}

With the rapid development of computer technology and network technology, a large number of diverse services emerged, the competition between service providers becomes increasingly fierce. In order to win in the fierce competition, service providers must ensure that their services could be recognized by the user.

Joseph Pine, in the "experience of the economy", predicted that the future economic development belongs to the era of economic experience. Experience economics aim to meet the user's positive self-satisfaction, and emphasize the self-experience in the consumer process. Those main features are the performance of sensory, personalized and participatory. The user's demand for the product is no longer limited to functional satisfaction, but also the user's psychological needs. So, the user experience attracts more attention by domestic and foreign scholars and business community.

The user experience is first proposed by Norman, pointing out that a successful user experience must be done without harassing, without the user's boredom to meet the needs of customers; secondly, the products should be simple and elegant so that customers will accept it with the pleasure and joy. In addition, it should bring users additional surprises [1]. As the expansion of user experience in content and architecture, the meaning of the user experience is constantly expanding [2].

In recent years, the usability, user-centric design, perceptual engineering, interactive experience, emotional design and other areas closely related to the user experience, but the real meaning of the user experience, the specific content and the evaluation method did not form a consensus.

There are different opinions on the concept of user experience. This paper intends to proceed from the concept and composition of user experience summarize the evaluation, development and application of user experience. Trying to summarize a set of standards related to the concept of user experience. From a large number of statements and standards, we try to find a unified expression. At the same time, by summarizing the hotspot of user experience research and the shortcomings, we try to explore the user experience needs further study of the problem. 


\section{The Concept and Composition of the User Experience}

2.1 The Concept of the User Experience. User experience is an extension of interactive technology, which is to research the quality of interactive technology from the perspective of product structure, product quality to the user's emotional needs [3]. Law et al. in 2009 analyzed and summarized several forms of user experience definitions in 275 investigators and user experience practitioners, and pointed out that the user experience is dynamic, environmentally dependent and subjective [4], the above characteristics and user experience research multi-disciplinary cross and other factors caused in the definition of user experience is not unified.

From the point of view of the content of the user experience, the literature generally believe that the user experience involves users, products and interactive environment in these three areas. The most influential definition of user experience is the definition given by ISO 9241-210: all responses and results for products, services, or services that are used or expected to be used [5]. This definition points out that the user experience is generated by the user interaction with the product, including the user's psychological feeling, physical sensation and user experience. The result is mainly the user's perception and response, including emotional and physiological reactions. Followed by the definition of the Usability Association (UPA), the user experience is summarized as all the user perception of all aspects of the product, service, or business interaction [6].

2.2 The Composition of the User Experience. So far, in the composition of the user experience, there are several more representative theories: situational experience theory [7], user participation theory (User Engagement) [8], the best experience theory (Flow Experience) [9] etc. The situational experience theory shows that the user experience includes the direct experience and the indirect experience. The direct experience refers to the experience of the user in the real environment. The indirect experience refers to the user's experience in the virtual environment. The user participation theory points out that the user experience includes aesthetics, usability, attention, feedback, motivation, perceived control, and sensory appeal; the best experience theory points out that user experience research attributes include usability, user skills, challenges, attention, pleasure, awakening and telepresence.

\section{Evaluation Criteria for the User Experience}

The user experience evaluation method can be divided into the construction model for evaluation and direct evaluation. Among them, the user experience evaluation model is to use multiple regression analysis, linear programming, nonlinear programming, structural equation model and other methods to establish the user experience and the relationship between the elements of the model to evaluate the user experience level. Direct evaluation method is based on user experience. The questionnaire is used to obtain the user experience data. After the data processing, the user experience scores and the total experience score are obtained, or the physiological indexes and behavior indicators data of the users are processed and evaluated according to certain evaluation criteria.

Quality of Experience (QoE) is a quantitative indicator of the user experience and is widely used to evaluate the quality of the user experience. At the same time, there are a lot of researches on the quantitative methods of user experience quality. At present, QoE research is generally focused on audio and video services. Some studies divide QoE in IPTV services into two components: (1) network-related QoE, expressed in QoEN; (2) user-related QoE, expressed as QoEU. The function model is as follows:

$$
Q o E_{N}=\frac{1}{\left(\text { Delay }+K_{1} \text { Jitter }\right) e^{\text {packetLoss }}},
$$

Where, Delay is the network delay; Jitter is the network jitter; K1 is the relative importance of adjusting the network delay and jitter; packetLoss is the packet loss rate.

$$
Q o E_{U}=\frac{\log _{10}\left(v_{q}\right)}{t_{\text {zap }}+K_{1} t_{\text {sync }}} \text {, }
$$


Where, $v_{q}$ is the quality of the video; $t_{\text {zap }}$ is the time used to convert the channel; $K_{1}$ is the importance of adjusting the $t_{\text {zap }}$ and $t_{\text {sync }} t^{t_{\text {sync }}}$ is the synchronization error between the video and audio.

\section{The Development and Application of the User Experience}

Most of the applications of user experience research focus on web and electronic products. Bargas-Avila in the literature [11] made the statistics of the user experience research object ratio, they pointed out that electronic products (mobile devices, games, etc.) accounted for $42 \%, 22 \%$ of art research, web research accounted for $12 \%$, the researchers conceived $9 \%$ of their own products. It summarizes the user experience through the literature in the website and electronic products in the application of research as follows.

4.1 The User Experience in Internet Business. User Website user experience research focused on the usability, aesthetics, simplicity, fluency and other aspects. The study of website usability has been a hot topic in academic research. Huang gives the reason for the importance of website usability research, pointing out that usability issues can lead to losses of users and economic loss [12]. O'Brien studied the influencing factors of the user experience of the online shopping site, constructed a model of the relationship between pleasure and motivation and user participation, and pointed out the factors that should be considered in the design of the shopping site [13]. Moshagen and Thielsch studied the influencing factors of the visual aesthetics experience of the website, and studied the website design problem from the aspects of simplicity, diversity, color and technology. The example shows that the developed scale can effectively evaluate the visual aesthetic experience of the website [14].

4.2 The Composition of the User Experience. At present, the replacement speed of the communication and entertainment equipment is unprecedented. Park et al. [15] constructed the five models of user experience and the relationship between usability, emotion and user value, and he provided the idea for the quantitative study of user experience and pointed out that the nonlinear model is the future trend of user experience. Luo et al. proposed a scenario-based user experience design method, and use the mobile phone interface design as an example to verify the method. With the popularity and use of mobile devices, how to make mobile devices in the appearance of attracting users to produce the desired experience, the senses in the purchase of motivation and the use of the process of generating customer loyalty is the hot spots of the user experience in mobile applications.

\section{Conclusion}

This paper focuses on the research results of user experience definition, composition and evaluation criteria, and summarizes the development and application of user experience. In the literature, it is found that the existing research has different understanding of the user experience due to the different research background and the researcher's background. The difficulty of user experience research leads to the divergence of conclusion of user experience. The purpose of user experience research is to find the design elements that affect the user experience, by optimizing the product design we try to enhance the level of user experience, and ultimately enhance customer loyalty. Therefore, the future study should pay attention to the following points: aiming to continuously expand the user experience research applications, especially the integration of a variety of evaluation indicators evaluation methods; taking into account the user experience of the dynamic; user experience is related to physical, psychological, behavioral science and other subject, therefore, the measurement and evaluation of user experience research should combine the research results of the above in order to study the user's perception, psychology, decision-making process. 


\section{References}

[1] Norman D, Miller J, Henderson. What you see, some of what's in the future, and how we go about doing it: $\mathrm{HI}$ at Apple Computer [C]. Conference companion on human factors in computing systems, Massachusetts, ACM, 1994: 155-155.

[2] Seapin D L, Senach B, Trousse B, et a1. User Experience: Buzzword or New Paradigm [C]. ACHI 2012, The Fifth International Conference on Advances in Computer-Human Interactions, Valencia, Netherlands, XPS, 2012: 336-341.

[3] Hassenzahl M. User experience (UX): towards fin experiential perspective on product quality [C]. Proceedings of the 20th International Conference of the Association Francophone d' Interaction Homme-Machine. Metz, New York, ACM, 2008: 11-15.

[4] Law E L C, Roto V, Hassenzahl M, et a1. Understanding scoping and defining user experience: a survey approach [C]. Proceedings of the SIGCHI Conference on Human Factors in Computing Systems. Boston, New York, ACM, 2009: 719-728.

[5] ISO. 9241-210: 2010. Ergonomics of human system Interaction-Part 210: Human-centered design for interactive systems (formerly known as 13407). International Organization for Standardization (ISO). Switzerland, 2010: 7-9.

[6] UPA (Usability Professionals’ Association), Usability Body of Knowledge.

[7] Toffier A. Future shock [M]. Random House Digital, Ina, 1984.

[8] Kearsley G, Shneiderman B. Engagement Theory: A Framework for Technology-Based Teaching and Learning [J]. Educational technology, 1998, 38(5): 20-23.

[9] Csikszentmihalyi M, Csikszentrnihalyi I. Beyond boredom and anxiety: The experience of play in work and games [M]. San Francisco: Jossey-Bass, 1975.

[10] Morville P. User experience design.

[11] Bargas-Avila J, Hombaek K. Foci and blind spots in user experience research [J]. Interactions, 2012, 19(6): 24-27.

[12] Huang. A research taxonomy for e-commerce system usability [C]. In Proceeding of the 8th Americas Conference on Information System, Dallas, 2002: 638-642.

[13] O'Brien H I. The influence of hedonic and utilitarian motivations on user engagement: The case of online shopping experiences [J]. Interacting with Computers, 2010, 22(5): 344-352.

[14] Moshagen M, Thielsch M T. Facets of visual aesthetics [J]. International Journal of Human-Computer Studies, 2010, 68 (10): 689-709.

[15] Park J, Han S H, Kim H K, et a1. Modeling user experience: A case study on a mobile device [J]. International Journal of Industrial Ergonomics, 2013, 43: 187-196. 